\title{
Produção de Vida e Processos de Criação no Trabalho Docente
}

Daniele Amaral de Sá

\section{RESUMO}

Este artigo busca analisar a relação entre o processo de adoecimento docente e o modelo político-econômico atual, evidenciando as capturas e rupturas frente à realidade desafiadora do trabalho no espaço escolar. É visto que os professores veem-se muitas vezes paralisados e enfraquecidos frente às heterodeterminações do trabalho, o que produz adoecimento e limita as possibilidades de mudança num movimento de naturalização da realidade. Neste sentido, a gestão do trabalho e seus atravessamentos são colocados em análise, especialmente as práticas de culpabilização e individualização das problemáticas vivenciadas na escola. A partir da apresentação destas contradições são discutidas as possibilidades da invenção de caminhos que potencializem a produção de saúde do trabalhador por meio dos processos de criação e o aumento do poder de agir. Como base para esta discussão buscou-se como interlocutores os estudos de Clot (2006) e Schwartz (2004), tendo como suporte teórico-metodológico as contribuições da Clínica da Atividade.

Palavras-chave: Produção de Subjetividade. Trabalho Docente. Processos de Criação no Trabalho Docente. Saúde.

\section{Life Production and Creation Processes in the Teachers Work}

\section{ABSTRACT}

This paper intends to analyze the relation between the process of teachers illness and the existing economic politics model, highlighting the captures and split front the challenging reality of work into the educational space. It is seen that the teachers notice themselves many times paralysed and weakened in the face of job heterodeterminations, producing illness and limiting the changes possibilities in a movement of reality naturalization. In this direction the work management and its crossing are put in analyses, espeacilly the guilt and individualization

1 Mestre em Psicologia Institucional pela Universidade Federal do Espírito Santo. Psicóloga. E-mail: daniele_as@hotmail.com 
practice of the issues experienced in the school. From the presentation of this contradictions, we dicuss the possibilities of invent ways which enhance the production of worker health through the creation process and the raise of acting power. As base for this dicussionwas it was used as interlocutors the researchs of Clot (2006) and Schwartz (2004), having as a methodological and theoreticalsupport theClinical Activity contributions.

Keywords: Subjectivity Production. Teachers Work. Creation Processes in Teachers Work. Health.

\section{Producción de Vida y Procesos de Creación en el Trabajo Docente}

\section{RESUMEN}

Este artículo busca analizar la relación entre el proceso de enfermedad docente y el modelo político económico actual, evidenciando las capturas y rupturas frente a la realidad desafiante del trabajo en el espacio escolar. Es visto que los profesores se ven muchas veces paralizados y debilitados frente a las heterodeterminaciones del trabajo, produciendo enfermedad y limitando las posibilidades de cambio en un movimiento de naturalización de la realidad. En este sentido la gestión del trabajo y sus atravesamientos se ponen en análisis, especialmente las prácticas de culpabilización e individualización de las problemáticas vivenciadas en la escuela. A partir de la presentación de estas contradicciones se discuten las posibilidades de la invención de caminos que potencien la producción de salud del trabajador por medio de los procesos de creación y el aumento del poder de actuar. Como base para esta discusión se buscó como interlocutores los estudios de Clot (2006) y Schwartz (2004), teniendo como soporte teórico y metodológico los aportes de la Actividad Clínica.

Palabras clave: Producción de Subjetividad. Trabajo Docente. Procesos de Creación en el Trabajo Docente. Salud.

\section{Introdução}

O objetivo deste artigo é expor a necessidade dos processos de criação no trabalho para a manutenção da saúde, entendendo criação como possibilidade para autogestão, aumento do poder de agir e po- 
tencialização do sentido do trabalho. Uma necessidade inerente ao humano.

A atividade, conceito tomado por Yves Clot (2006) da ergonomia, assume um sentido amplo na proposta da Clínica da Atividade, abarcando também o nível psicológico da ação. Além de ser a atividade aquilo que se faz e a tarefa, aquilo que se tem a fazer, Clot (2006) trabalha a partir do que chama de o real da atividade, ou seja,

[...] aquilo que não se faz, aquilo que não se pode fazer, aquilo que se busca fazer sem conseguir - os fracassos -, aquilo que se teria querido ou podido fazer, aquilo que se pensa ou que se sonha poder fazer alhures. [...] aquilo que se faz para não fazer aquilo que se tem a fazer ou ainda aquilo que se faz sem querer fazer. Sem contar, aquilo que se tem de refazer. (p. 116)

Neste sentido, o conceito de atividade mostra-se uma importante ferramenta para pensar o caráter processual e irrepetível do trabaIho, meio de constituição do trabalho e do trabalhador.

Quando o profissional se depara com as infidelidades nos processos de trabalho, acaba desenvolvendo estratégias para lidar com elas, de forma a regular sua atividade. A este momento de gestão do trabaIho, Yves Schwartz contribui com a noção de uso de si por si e uso de si pelo outro, apresentando o campo de trabalho como uma constante tensão e efeito de negociações diversas, a fim de garantir o objetivo do trabalho (SCHWARTZ, DURRIVE, 2010).

É no vazio das normas, ou seja, quando estas não dão conta da realização da tarefa, que é possível ao trabalhador criar, se posicionar como num jogo entre o que lhe é importante realizar, o que lhe é exigido por seus pares, o que os alunos demandam, dentre outros. Neste momento, a atividade emerge, não numa ação passiva, mas numa ação criadora em que o professor não detém o controle absoluto sobre ela, mas é também efeito desta constituição.

Neste contexto, para compreender o processo de adoecimento do professor, é importante analisar como se constituem as práticas engendradas na escola. Quais relações forjam o professor e seu trabalho e como se dão o modo de viver e trabalhar na atualidade?

Desta forma, inicialmente são abordados e contextualizados os mecanismos de formação do trabalho e do trabalhador, configurando 
as estratégias de luta pela manutenção da saúde e os enfraquecimentos forjados nas políticas de gestão que perpassam o cotidiano escolar. A última seção traz como contribuição a análise do trabalho a partir do processo de criação e estilização por dentro do gênero profissional, destacando a relação desta dinâmica com o aumento do poder de agir do trabalhador. Neste sentido, ressalta-se a possibilidade do surgimento de brechas para a criação de outros modos de existência por meio do questionamento e subversão das normas, a partir da construção de outras formas de gerir o trabalho aliados à produção de saúde.

Este trabalho foi construído a partir do suporte teórico-metodológico da Clínica da Atividade e tem como base as discussões iniciadas na pesquisa de mestrado "Produção de Vida no Trabalho Docente"2, cujos resultados somaram-se a outras experiências e encontros com o trabalho do professor, dialogando também com algumas contribuições da filosofia da diferença.

\section{Produção do trabalho e do trabalhador}

Para analisar o processo de produção do trabalho e do trabalhador docente, é necessário discutir as relações que constroem a atividade docente para além dos muros da escola. As paisagens que se configuram no território escolar estão relacionadas ao modo como o habitamos e construímos, os quais são atravessados pelos aspectos políticos e econômicos vigentes. Longe de ser uma construção apenas individual, é, por sua vez, tecido em meio a uma trama complexa de relações políticas de gestão ${ }^{3}$ da vida. Assim, é necessário entender quais modos que são gestados no mundo do trabalho, constituem o trabalhador docente e o trabalho. Para análise, serão apresentadas algumas situações ${ }^{4}$ vivenciadas na escola.

2 Dissertação de mestrado "Produção de vida no trabalho docente" (Sá, 2011) buscava analisar o processo de produção do trabalho e do trabalhador docente, sinalizando alguns aspectos deste coengendramento eu-mundo, abarcando processos de construção da saúde e do adoecimento.

3 Aqui gestão não tem um sentido administrativo, mas evoca um sentido mais amplo, referindo-se às relações estabelecidas com diversas instâncias e as regulações, diálogos, escolhas que precisam ser realizadas, seja em relação ao sistema político educacional, ao tempo, à comunidade escolar, ao processo de trabalho, dentre outros. As relações que se estabelecem com esses diversos elementos é que produzem os modos de fazer. Gestão neste sentido, não é um lugar, uma posição social, mas uma prática inerente a todo sujeito.

4 Os relatos e cenas que fazem parte deste artigo são fragmentos de pesquisa realizada com 
Cena 01

Pedimos para Secretaria de Educação diminuir o número de crianças por sala de aula, mas a Secretaria mandou medir as salas para saber quantos alunos cabiam por metro quadrado (relato de uma professora).

Cena 02

Notei que a professora não estava bem, estava muito quieta, parecendo aborrecida. Perguntei o que estava acontecendo. Ela disse que não estava se sentindo bem naquela escola, não encontrava parceria, não tinha um vínculo sólido com as outras duas professoras do primeiro ano. Disse que uma das professoras guarda tudo pra si, não compartilha o que está fazendo, não troca. A outra constantemente pega licença por não aguentar a escola, está sempre na defensiva, atacando as outras professoras e reclamando. Tem se sentido sozinha no trabalho, e ainda há muita cobrança. Se sente em falta com as crianças. Disse que recebeu uma turma muito boa, que poderia estar avançando muito mais, no entanto, acha que está deixando a desejar. Se preocupa com a próxima professora que pegar a turma dela, pensa que ela pode avaliá-la e ver que não realizou um bom trabalho com a turma. Disse que tem muita coisa atrasada, tem vários planos para colocar em dia, preparar mural, dar atividades que estão faltando. Haverá uma exposição na escola e ela precisa correrpara confeccionar trabaIhinhos para serem expostos. Anda também preocupada com esta exposição, pois tem virado motivo de competição entre os professores que não se ajudam [...]. Diz que o que mais a faz sofrer é a falta de tempo, que a impede de realizar seu trabalho. Gostaria da presença de uma estagiária para ajudá-la. (Diário de Campo).

Os dois trechos são exemplos de situações comumente vivenciadas na escola. A dificuldade de diálogo com a Secretaria de Educação, o tratamento das questões por um viés burocrático e padronizado, como a quantidade de alunos por sala de aula, a vivência dos problemas de forma isolada e individual, a falta de tempo para conversar sobre as experiências do trabalho, o sentimento de fracasso, a produção de um clima de competição entre os professores, dentre outros. Estas questões são analisadas a partir das práticas que as constituem, entendendo-as

professores de escolas públicas municipais da Grande Vitória, ES. 
não como locais e individuais, mas conectadas a uma forma vigente de trabalhar e se relacionar.

De fato, a estrita heterodeterminação das normas de agir, nos parece simultaneamente impossível, o meio é sempre em algum grau infiel, inantecipável e invivível (SCHWARTZ; DURRIVE, 2010). A escola, muitas vezes, é dividida e organizada numa tentativa de padronização das relações naquele espaço, buscando a previsão e a homogeneização das ações. Uma organização que não tem origem somente em fins pedagógicos, mas é perpassada pela organização econômico-produtiva.

A seguir, outra expressão que mostra a precariedade do espaço escolar e o empobrecimento de suas relações, gerando sentimentos ambivalentes e desqualificadores sobre o lugar tanto do professor como do aluno naquele espaço. "Na escola é assim: o professor finge que ensina e o aluno finge que aprende, porque com essas condições não dá pra trabalhar!" (relato de um professor). A falta de investimento nos setores públicos aliados ao enfraquecimento da aposta na potência dos espaços públicos gera, como afirma Linhares, certo cinismo:

\begin{abstract}
A gravidade dessa situação tem sido expressa [...] como um desânimo que, contagiando professores e estudantes, acaba por obstruir os caminhos da aprendizagem e do ensino, revestindo-os ora de negligência que beira o cinismo, ora de um tipo de rebeldia que não perde a oportunidade para danar os processos escolares, do que o patrimônio material constitui um bom exemplo pela sua visibilidade (LINHARES, 2005, p. 6).
\end{abstract}

Na cena 1, quando a Secretaria de Educação calcula o número de crianças que cabem na sala de aula por metro quadrado, esta demonstra priorizar no processo de aprendizagem condições-padrão para uma aprendizagem-padrão, não levando em conta as especificidades do processo educativo em situações concretas. Esse posicionamento encontra fundamentos num modo de trabalhar embasado em políticas produtivistas, em que apenas os valores dimensionados, os que possuem unidades de medida para comparar sua grandeza, são considerados. No entanto, esses são bens não mensuráveis, dimensões do trabalho na escola que não podem ser quantificáveis (SCHWARTZ; DURRIVE, 2010). Como, então, dar corpo a esses valores sem dimensão5?

5 Os valores que não podem ser mensuráveis dizem respeito a valores como a satisfação e 
Linhares (2005, p. 6) trata essas questões como um desafio na formação docente, e caracteriza um pouco mais essa situação vivida pelos professores: "[...] um acúmulo de tarefas se sobrepõe no cotidiano escolar, fazendo com que o professor se sinta só, desamparado, sob condições de trabalho negativas e com desafios para os quais não se sente habilitado."

Muito do sentimento de indignação e paralisia frente aos problemas e demandas feitas ao professor se dá por este enfrentamento ocorrer a partir de estratégias individuais, sem sustentação da rede social ou mesmo sem discussão e uma maior responsabilização e integração do restante da população no debate.

Voltando à cena 02 , na qual aparecem os conflitos da professora em relação ao desempenho de seu trabalho, podemos perceber: (1) a queixa individualizada, entendendo-se como inteiramente responsável pelo sucesso de seu trabalho; (2) as ações cooperativas totalmente enfraquecidas; (3) o sentimento de impotência frente a mudanças no contexto vivido, como se dependesse exclusivamente da professora o estado das coisas em seu trabalho; (4) e ainda a falta de tempo para dar conta das tarefas do trabalho é entendida por ela como fruto de sua própria desorganização.

Na luta para alcançar resultados previstos pelos planejamentos definidos de forma heterônoma, muitas vezes, é preciso dançar conforme a música. No entanto, é impossível viver no previsto, ser fiel às prescrições do trabalho. E quando se erra o passo, não cumprindo as metas, o trabalhador é posto à margem. Os que não alcançam tais metas são tidos como improdutivos. A utilidade e a produtividade são centrais neste modo de produção e, com base nelas, regulam-se as relações: quem está fora, quem está dentro.

As práticas cada vez mais individualizadas acabam gerando maior desânimo e sentimento de impossibilidade de transformação. Cada professor é tido como responsável pelo sucesso de seu trabalho, por sua turma. Pelo descrédito no trabalho coletivo, os espaços de conversa, planejamento e avaliação são ocupados por trabalhos atrasados. O tempo de planejamento e de troca de experiências entre os profissionais muitas vezes não é entendido como trabalho, é encarado como momento supérfluo e sem aproveitamento. Entretanto, atribui-se gran-

a saúde, os quais não podem ser quantificáveis, no entanto, podem ser implementados indicadores para distingui-los (SCHWARTZ, 2004). 
de valor aos momentos de formação continuada ou progressão quando os professores assistem a palestras informativas, muitas vezes, sem discussão da prática docente. Aqui, mais uma vez indicamos a prioridade atribuída ao que é dimensionável na educação ${ }^{6}$.

Outro aspecto que a cena 02 indica é a acentuação da competitividade entre os trabalhadores em detrimento de práticas coletivas na construção de um plano comum. A competitividade sustentada pela lógica de um indivíduo detentor de capacidades para gerar seu próprio sucesso e crescimento dentro de condições materiais básicas continua sustentada pela lógica da liberdade individual. Assim, o fortalecimento da competitividade é associado a um crescimento e desenvolvimento por atuar como incentivo para uma maior produtividade. Neste sentido, é possível observar que as relações crescentemente competitivas trazem como efeito a diminuição das práticas solidárias, o desinvestimento no trabalho em conjunto, sendo o ambiente escolar considerado muitas vezes como campo de batalha onde sobrevive o mais forte.

A acentuação das desigualdades e hierarquização se dá também pela presença de um modelo de profissional-padrão, sendo este o professor que dá conta do trabalho sem reclamar da falta de estrutura. Vemos em alguns casos que o professor-modelo é aquele que, por falta de condições básicas para realizar sua tarefa, compra com seu próprio dinheiro os materiais necessários para a atividade proposta, suprindo também com seu trabalho a falta de outros funcionários e a precariedade do sistema educacional público. Esse tipo de atuação é elogiada por sua eficiência e produtividade.

A questão se coloca quando as regras, as metas a serem atingidas não são estipuladas pelo coletivo de trabalhadores e nem problematizadas. O que vai à contramão da ampliação do poder de agir dos coletivos de trabalho é, exatamente, as tentativas de redução de autonomia, a tentativa de amputação da potência inventiva dos humanos. Nos relatos dos professores, a busca de um trabalhador-modelo está sempre presente. O bom professor é aquele que consegue aprovar todos os alunos. Segundo Barros (2004, p. 106),

$6 \mathrm{Na}$ perspectiva apontada, é levada em conta a quantidade de cursos realizados pelos professores, o que não é a mesma coisa que tratar de formação, um valor não mensurável, o qual não se dá apenas pela via da educação formal. 
No modo de produção capitalista, por exemplo, a busca da homogeneização da existência, a tentativa de modular os processos inventivos de subjetivação/ trabalho e a produção de repetição em detrimento de criação são a tônica de seu funcionamento." (BARROS, 2004, p. 106).

O que contribui para a diminuição da potência dos professores é também a naturalização das experiências de sofrimento imobilizador e frustração no trabalho, quando não se sentem capazes de mudar as situações, sem autonomia, como se não fossem gestores da sua atividade.

\section{Produção de subjetividade e trabalho}

As práticas atualizadas na escola não são naturais daquele espaço e nem de autoria única dos trabalhadores, mas se encontram conectadas a processos de subjetivação em curso na contemporaneidade. São estes processos que se conectam ao modo de trabalhar e ser trabaIhador.

As diferentes modulações do modo de produção capitalista geram relações sociais pautadas na desigualdade e na competição. Como afirma Fonseca (2002), é no modo de trabalhar que esta organização econômica e social se torna mais explícita, sendo possível percebê-la por seus efeitos a partir de tecnologias de gerenciamento dos recursos e da força de trabalho. Estes ritmos de produção empreendem tom e cadência aos modos de trabalhar.

O trabalho não possuindo uma essência, ou um formato natural é contingente aos modos de produção e aos princípios econômicos vigentes. Uma mudança no modo de trabalhar está atrelada à transformação dos sistemas econômicos e de governo. A organização do trabalho emerge juntamente com as políticas e princípios a ele ligados. Na idade média, por exemplo, o modo de produção artesanal dava outra forma ao trabalho, caracterizando-se pela detenção dos meios de produção pelo trabalhador, como também sua gestão sobre todo processo produtivo, chegando a uma experiência com o trabalho ligada a uma busca de perfeição sem modelos, mas buscando superar a si próprio, como autor da obra artesanal. A forma de lidar com o tempo era ritmada muito mais pela especificidade do trabalho e a necessidade do próprio trabalhador na produção do objeto do que pela demanda do comprador. 
Atualmente existem tecnologias que dão outro ritmo ao trabalho, marcado por individualismo, competição exacerbada, que não ficam apenas nas fábricas. Este modo de trabalho rápido, produtivista, em busca exclusivamente de resultados constitui as relações diárias, nos diferentes espaços onde a vida acontece. Esta forma de organizar o trabalho se materializa na escola e se materializa nas múltiplas práticas nela engendradas.

Os modos de funcionamento escolar, as relações com o aprender e a produção de conhecimento, assumem ao longo do tempo formas diversas. A prática docente vai se forjando num processo histórico. Como afirma Linhares (2005), o objetivo do ensino e os princípios que o envolviam mudaram tendo hoje um objetivo diferente de épocas anteriores. Esta transformação do objetivo escolar não é uma evolução, mas tem ligações com as mudanças políticas e socioeconômicas, sobre o que é valorizado e priorizado.

É possível perceber as ressonâncias do modo produtivo atual na escola. A tentativa em excluir os professores e demais atores da comunidade escolar das discussões sobre a gestão da escola é um sinal deste processo. Nisto percebemos a tentativa de uma separação entre o trabalhador e o processo de organização do trabalho e ainda uma maior hierarquização. O que perpassa esta lógica de funcionamento é a ideia do trabalho como simples execução de normas e prescrições, no entanto, esta lógica é insustentável.

As práticas que se efetivam na escola como em todas as relações sociais cotidianas são marcadas pelos processos de subjetivação vigentes. Há uma reorganização e um redimensionamento do valor que se atribui às práticas. É justamente por esta forma de propagação sutil, rápida e eficaz que os princípios que regem essas relações aparecem de forma diluída e disfarçada em nossas práticas, sendo difícil nos darmos conta de suas referências, passando normalmente como "atitudes naturais" do viver em sociedade. Esta organização econômica posta em funcionamento pelos humanos, organiza e direciona, estando presente em todas as relações por um processo de produção subjetiva. Guattari e Rolnik (1986) afirmam que a reprodução de determinada forma subjetiva não se dá de uma ora para outra, mas conta com uma formação que se faz por meio de um ambiente maquínico.

[...] é evidente que para fabricar um operário especializado não há apenas a intervenção das escolas pro- 
fissionais. Há tudo o que se passou antes, na escola primária, na vida doméstica - enfim, há toda uma espécie de aprendizado que consiste em ele se deslocar na cidade desde a infância, ver televisão, enfim, estar em todo um ambiente maquínico. (GUATTARI; ROLNIK, 1986, p. 27)

A este processo de produção e regulação da vida Foucault (2011) dá o nome de biopoder. Um poder que age sobre a vida com técnicas de controle implícitas, fazendo o próprio sujeito pensar que advém dele esta regulação. $O$ controle neste exercício do poder é incorporado ao sujeito. A sensação de liberdade e livre escolha sobre a própria vida tornam o sujeito facilmente gerido pelos mecanismos do biopoder, sendo ele inteiramente responsabilizado por seu sucesso ou fracasso. Não é possível reconhecer um poder localizado, pois sua forma está nos mecanismos de controle e não numa pessoa ou organização. Assim, por meio de uma proposta de liberdade entendida como livre escolha e concorrência, defesa da liberdade individual e da propriedade privada, vê-se a regulação da vida como se ficasse a cargo de um movimento natural dos indivíduos, um movimento que acarreta numa mercadorização da vida.

A partir do que afirmam Machado e Lavrador (2010), podemos dizer que o adoecimento docente faz parte dos processos de subjetivação em curso. Daí a necessidade de analisar e questionar "o que estamos fazendo de nós mesmos?" Analisar estes sinais a partir de sua produção histórica, e inserida em um mecanismo de produção que não está encerrado nos muros da escola. "Cabe a nós procurarmos entender o que vem acontecendo, as angústias que se produz, os medos, os cansaços". (MACHADO, 2004, p. 166).

\section{Produção de vida no trabalho docente}

Neste sentido, é importante analisar a produção do sofrimento e as possibilidades de produção de saúde no trabalho. As situações que levam ao sofrimento no trabalho constantemente estão associadas a um impedimento da ação e a uma falta de sentido em relação à atividade realizada, configurações que limitam o grau de ação do trabalhador.

Não são os conflitos que paralisam o trabalhador, mas a estagnação diante deles. Como afirmam Bendassolli e Soboll (2011, p.14) as possibilidades de transformação no trabalho passam pela busca em 
restituir "sua dimensão ontológica-chave: a de confronto do homem com a natureza, consigo mesmo e com os outros." Pois é por meio desse enfrentamento que o sujeito se desenvolve. É exatamente a forma de enfrentamento das problemáticas que gera um aumento ou uma diminuição na potência de vida. A saúde não é entendida aqui como uma ausência de doença ou harmonia em relação aos vários aspectos da vida, mas entendemos saúde como normatividade, possibilidade de produzir novas normas que desviem das situações que constrangem a vida, que possam subvertê-las ou transformá-las.

Podemos dizer que a atividade é produtora de laços entre o sujeito, os outros e o real, estando assim, intimamente ligada a promoção de saúde. A qualidade da mediação que a atividade opera é determinante neste processo. No entanto, a atividade pode ser ou não geradora de saúde, dependendo do quanto tem cumprido seu papel na criação de vínculos e conexões com o mundo e com os outros.

Quanto mais se reduzem os níveis de intervenção do trabalhador em poder modificar seu fazer, mais diminui a produção de prazer gerada pela realização da tarefa. Quando o trabalhador não pode conduzir seu trabalho de forma a pôr nele algo de si, ou seja, compor com sua vida, este se torna enfadonho e produtor de um sofrimento paralisante. Neste sentido, podemos dizer que, muitas vezes, o motivo de cansaço do trabalhador é a atividade impedida. Quando o trabalhador se vê como um objeto da prescrição da tarefa é diminuída sua potência de vida.

É impossível ao trabalhador ser inteiramente submetido aos modos de trabalhar vigentes, pois o ato é sempre singular, impossível de ser repetido, ele sempre surpreende as tentativas de antecipá-lo. Esta forma singular de realizar o trabalho, apesar da existência de regras pré-estabelecidas, Clot (2006) define como estilo. O estilo é a transformação das ações esperadas, a reformulação de um gênero profissional. O gênero é

o sistema aberto de regras impessoais não escritas que definem um meio dado, o uso dos objetos e o intercâmbio entre as pessoas; uma forma de rascunho social que esboça as relações dos homens entre si para agir sobre o mundo."(CLOT, 2006, p. 50).

O gênero define o que é aceitável e inaceitável no trabalho, age como uma espécie de fronteira para a ação do trabalhador. No entanto, 
esta fronteira não é fixa, sendo remodelada constantemente pelo processo de estilização. O gênero não determina a ação do trabalhador, mas é antes um recurso para ela.

O que ressalta nesta discussão sobre gênero e estilo é a referência que fazem ao caráter irrepetível da atividade o que se demonstra por meio dos estilos de trabalho. A impossibilidade de repetição da ação nos parece um indicativo de que mesmo a vida sendo marcada por processos que tentam modelá-la, o humano responde com a impossibilidade de uma repetição do ato. Então é possível perceber uma pista para a ruptura com modos de trabalhar que produzem uma sobrevida ao invés de uma vida em constante expansão e desenvolvimento.

Entretanto, a invenção de um novo modo de ser e fazer não se dá a partir do nada. Ao trabalhar, o trabalhador não inventa um novo gênero, mas o transforma por dentro dele mesmo, usa de suas próprias configurações para fazer uma metamorfose. Os gêneros são meios e objetos da ação do trabalhador. O estilo transforma o gênero provocando seu desenvolvimento, ou seja, sua variação. É importante percebermos que a estilização não é um processo que se dá à parte das normas do trabalho, mas joga com elas, transforma a partir delas. "O estilo só age sobre os objetos em segundo grau, nunca de modo direto e somente por intermédio de gêneros [...] ponto de vista mais ou menos estabilizado de que ele [o trabalhador] se serve como um instrumento." (CLOT, 2006, p.197).

Assim, Clot (2006) afirma que não havendo a criação, há a recriação, o gênero seria desta forma um recurso para a ação, base para a criação. No entanto, esta criação não tem como matéria prima apenas o gênero profissional, pois o estilo não surge por pura intenção do trabalhador em variar o gênero, mas pelo confronto, nascido de uma relação conflituosa, o que Clot (2006) observa a partir da referência de Bakhtim sobre o estilo literário. O estilo "vive nos confins de conflitos que agitam as duas memórias da atividade" (p.197) a memória pessoal e a memória impessoal relativa ao gênero. Neste sentido, vemos que o estilo não é algo individual, mas aponta para um jogo de forças no qual é produzido.

A forma do gênero ser atualizado no fazer do trabalhador traz sempre uma variação, pois coloca em cena o que este entende ser importante para o desenvolvimento da atividade. Deste modo, o gênero não está dado, 
[...] o estilo participa da renovação do gênero, o qual, no limite, nunca se pode dar por acabado. Ele vive mais ou menos intensamente de resto, das contribuições estilísticas que o reavaliam constantemente e Ihe dão sua dinâmica." (Clot, 2006, p.40).

Apesar de ser anterior ao ato por formar-se pela história da profissão, este é sempre inacabado, o gênero constrói o estilo e este por sua vez constrói o gênero.

Barros, Pinheiro e Zamboni (2010) fazem referência ao estilo a partir do devir, denunciando uma quebra com a forma de ver o mundo e os acontecimentos como construções lineares. Uma construção de mundo não linear permite uma ação que seja crítica ao presente, que produza crise com as formas de ser e fazer emergentes. É na aventura do presente que o vivo inaugura um novo vir a ser.

\footnotetext{
Quando estamos a falar na construção do presente, quando nos pomos a pensar em estratégias de resistência e criação que venham auxiliar na invenção de novos mundos para existir e novas formas de vida para viver não podemos deixar de olhar ao nosso redor para observar e registrar algo daquilo que nos é contemporâneo e que, paradoxalmente, se coloca como limite e como possibilidade de superação e ultrapassamento. Sim, nosso ponto de partida é o aqui agora (espaço-tempo) em que estamos mergulhados [...] (FONSECA; ENGELMAN; KIRS, 2006, p.84)
}

A ação, o movimento é o que proporciona a mudança e, portanto, é importante pensarmos em como tornar a ação nossa aliada na construção do presente. Quando se impede o movimento que garante o desenvolvimento da vida, esta se atrofia, então é preciso analisar que movimentos estamos produzindo e que outros estamos deixando de produzir. Analisar a engrenagem que produzimos e que nos produz. Neste sentido, nosso olhar se volta para o desenvolvimento do poder de agir em situação de trabalho para investigarmos e dispararmos os movimentos em favor da vida que por ora possam ter sido bloqueados.

O poder de agir não é impulsionado simplesmente por se ter uma tarefa a ser feita. Clot (2010, p.15) afirma que o poder de agir

[...] aumenta ou diminui em função da alternância funcional entre o sentido e a eficácia da ação em que se opera o dinamismo da atividade, ou seja, sua efi- 
cácia. [...] Por último, é o que na linguagem cotidiana, chama-se de cuidado [souci] e realização do "trabalho bem feito", aquele em que é possível reconhecer-se individual e coletivamente, sintonizado com uma história profissional que se persegue e pela qual cada um se sente responsável.

Ver sentido no trabalho, como indica Clot (2010), tem a ver com perceber-se como ativo no processo de criação de mundos. Ver-se no trabalho é também ver-se integrado a um coletivo que não é coletividade, mas um processo de produção eu-mundo. Ver-se como parte da transformação, e também transformador. Este sentido gerado no trabalho desenvolve o poder de agir, garantindo também a eficácia da atividade.

Uma análise da atividade que venha questionar modos de fazer que produzem a falta de sentido no trabalho é também uma forma de produzir vias sob o que parece estar dominado e acaba por impedir a ação. Afirmar e realimentar o caráter de movimento da ação é um dos objetivos para a produção de saúde no trabalho.

Quando a atividade não está a favor da vida, há a diminuição de sua potência, algo que impede seu poder de agir. A vida é garantida pela produção de meios que possibilitem sua expansão, os quais são produzidos pela atividade de trabalho. Como afirma Clot (2006, p.14), "a calibração do gesto é uma amputação do movimento", quando a atividade é heterodeterminada sempre há uma limitação da ação do trabalhador. Assim, podemos dizer que, quando a atividade encontra-se afirmando a força vital do sujeito, esta aumenta seu poder de ação, gerando uma "expansão nos modos de fazer o trabalho" (AMADOR; FONSECA, 2011, p. 18).

Como afirma Clot (2010), é importante sair do círculo vicioso instaurado pelos modos contemporâneos de viver, produzindo outros sentidos para o trabalho. Segundo Barros (2004), o que é necessário não é uma mudança, apenas, no que se faz, mas em como se faz. $O$ interesse está exatamente nas dimensões processuais do "como" e não reduzidas às funções ou tarefas. É no "como" que está o segredo e a surpresa, é no modo de fazer que se encontra a possibilidade de subversão das práticas atuais. $\mathrm{O}$ modo de pôr em prática o trabalho é que pode variar os princípios hegemônicos de gestão.

A captura por estes moldes de gerir o trabalho pode parecer intransponível, mas é na problematização exatamente do processo de trabalho que reside a possibilidade da emergência de modos instituintes de trabalhar e viver. 


\section{Considerações finais}

Como afirma Linhares (2005), é preciso estar sempre atento para conectar as práticas cotidianas aos movimentos político-econômicos mais amplos. E assim, questionar como é possível produzir outros modos de subjetivação diferentes dos atuais.

Ao dar moldes para o trabalho o modo de produção capitalista também dá moldes para quem exerce o trabalho. $O$ trabalho não se faz sozinho, o modo de trabalhar age imprimindo em quem o realiza também um modo de ser e de se relacionar. O ser e o fazer estão intimamente ligados, num processo constitutivo do ser. O fazer é o que permite sua existência, pois não há separação entre ambos. O ser e o fazer se dão numa relação de complementaridade e coengendramento em que um só se dá pela via do outro. O ser só existe em ação.

Entende-se a ação não como ato de simplesmente movimentar-se, deslocar-se, mas como impossibilidade da inércia absoluta do ser vivo. Não é uma determinação do ser a um fazer, mas uma criação do ser no fazer e do fazer no ser em que este último atua subvertendo as lógicas do trabalho e repetindo seus princípios.

Ao afirmar que o ser só existe como ação, como movimento, torna-se necessário questionar que movimentos se tem realizado. Se o fazer é ontológico, é necessário atentar como temos nos constituído. Em quais princípios o trabalho está alicerçado.

O trabalhador não se vendo como corresponsável pela produção da organização do trabalho nas suas diferentes dimensões: planejamento, execução, acompanhamento e avaliação, não se vê também como capaz de efetuar movimentos diferentes da lógica instituída. A produção de outras subjetividades passa também por um enfrentamento das formas subjetivas atuais. Passa pela produção de resistência em meio aos modos de organização do trabalho vivenciados.

Se existe algo natural à existência humana é sua capacidade de diferir, se transformar e sua incapacidade de se acoplar passivamente aos modelos de vida pré-determinados que insistem em querer nos modelar. Como afirma Pelbart (2008), quando parece que está tudo sob controle, tudo determinado e inerte, algo se movimenta de forma difusa e perturbadora. $\mathrm{O}$ autor afirma que "ao poder sobre a vida responde a potência de vida" (PELBART, 2008, p. 02), sendo que esta potência sempre esteve presente nas tentativas de adestramento das ações humanas. 
Esses processos de ruptura a certa lógica hegemônica são escritos por meio da constituição de outros modos de agir. Heckert (2002, 2004,2009 , 2010) aponta em seus trabalhos, ações que demonstram a viabilidade de processos de resistência frente às determinações sobre a vida. Estas formas de resistir são, no entanto "[...] processos anônimos e imprevisíveis, centelhas de instabilidade que tecem outros modos de existência. Resistir, como re-existência, criação de modos de agir que afirmam a inesgotável potência de criação que constitui o vivo." (HECKERT, 2004, p.14). A capacidade e a possibilidade de existir de outra forma são tomadas não como uma decisão pura e simples, mas como o próprio pulsar da vida, que se dá independente de uma escolha. Como afirma Heckert (2004), estes movimentos por mudança surgem cotidianamente como centelhas de instabilidade, algo como uma denúncia de que o que vivemos não está fechado em si. São as rachaduras nos modos de se fazer a vida que denunciam a possibilidade de desmoronamento e a capacidade de se erguer outras formas de viver.

Assim, muitas vezes não percebemos que o modo de produzir o trabalho é continuamente regulado, fazendo com que as rupturas sejam constantemente capturadas e acopladas num movimento que constrange e disciplina a vida, pois como observou Pelbart (2002 p.38): “[...] agora é a alma do trabalhador que é posta a trabalhar, não mais o corpo, que apenas lhe serve de suporte. Por isso, quando trabalhamos nossa alma se cansa como um corpo, pois não há liberdade suficiente para a alma, assim como não há salário suficiente para o corpo."É preciso haver liberdade para a alma, de forma que esta possa continuar se expandindo num movimento que é de desenvolvimento, não como acréscimo ou evolução, mas como transformação.

\section{Referências}

AMADOR, F. S; FONSECA, T. M. G. Atividade: o trabalho sob o signo do inacabamento. In: ROSEMBERG, D. S; ROCHI FILHO, J; BARROS, M. E. B. (Org.) Trabalho docente e poder de agir: Clínica da Atividade, devires e análises. Vitória: EDUFES, 2011.

BARROS, M; E; B. Modos de Gestão e Produção de Subjetividade. In: ABDALLA, M. BARROS, M; E; B. (Org.) Mundo e Sujeito: Aspectos Subjetivos da Globalização. São Paulo: Paulus, 2004. 
BARROS, M. E. B; PINHEIRO, D. A. L; ZAMBONI, J. Psicologia do estilo: nas bordas da atividade. Arq. bras. psicol., Rio de Janeiro, v. 62, n. 1, abr. 2010.

BENDASSOLLI, P. F; SOBOLL, L. A. P. Introdução às clínicas do trabalho: aportes teóricos, pressupostos e aplicações. In: BENDASSOLLI, P. F; SOBOLL, L. A. P. (Org.) Clínicas do Trabalho: novas perspectivas para compreensão do trabalho na atualidade. São Paulo:Atlas, 2011.

CLOT, Y. A função psicológica do trabalho. Petrópolis:Vozes, 2006. CLOT, Y. Trabalho e poder de agir. Belo Horizonte:Fabrefactum, 2010. FONSECA, T. M. G; ENGELMAN, S; KIRS, P. G. A revolução do presente. Revista do Departamento de Psicologia - UFF, v. 18, n. 2, p. 83-92, jul./ dez. 2006.

FOUCAULT, M. História da Sexualidade: a vontade de saber. Rio de Janeiro: Graal, 2011.

GUATTARI, F. e ROLNIK, S. Micropolítica:cartografias do desejo. Petrópolis: Vozes, 1986.

HECKERT, A. L. C; ALGEBAILE, E. B. Formação e mudança: reflexões compartilhadas. TEIAS, Rio de Janeiro, ano 3, n 5, jan/jun 2002.

HECKERT, A. L. C. Narrativas de resistência: educação e políticas.Tese (Doutorado em Educação)-Universidade Federal Fluminense, Niterói, 2004.

HECKERT, A. L. C; LINHARES, C. Movimentos Instituintes nas Escolas: Afirmando a potência dos espaços públicos de Educação. ALEPH, ano IV, n 12, junho 2009.

HECKERT, A. L. C; ANDRADE, R. B. Caminhos bifurcantes na educação inclusiva: inclusões e rebeldias silenciosas na educação pública. Fractal: Revista de Psicologia, v. 22 - n. 3, p. 497-512, Set./Dez. 2010.

LINHARES, C. Políticas de formação de professores e experiências instituintes. ALEPH, Ano 1, n. 5, maio/junho, 2005.

MACHADO, L. D. Capitalismo e Configurações subjetivas. In: ABDALLA, M. BARROS, M; E; B. (Org.) Mundo e Sujeito: Aspectos Subjetivos da Globalização. São Paulo: Paulus, 2004.

MACHADO, L. D; LAVRADOR, M. C. C. As políticas que incidem sobre a vida. Estud. pesqui. psicol., Rio de Janeiro, v. 10, n. 1, abr. 2010. 
PELBART, P. P. Vida e morte em contexto de dominação biopolítica. Conferência no Ciclo O Fundamentalismo Contemporâneo em Questão. Instituto de Estudos Avançados (IEA) da USP. 3 out. 2008.

PELBART, P. P. Poder sobre a vida, potência da vida. Lugar Comum, n17, p. 33-43, 2002.

Sá, D. A. Produção de vida no trabalho docente. 2011. $134 f$. Dissertação (Mestrado em Psicologia Institucional) - Universidade Federal do Espírito Santo, Vitória, 2011.

SCHWARTZ, Y.Circulações, dramáticas, eficácias da atividade industriosa. Trabalho, Educação e Saúde, v. 2, n. 1, p. 33-55, 2004

SCHWARTZ, Y; DURRIVE, L. (Org.). Trabalho \& ergologia: conversas sobre a atividade humana. Niterói: EdUFF, 2010.

Recebido: Janeiro/2018

Aceito: Julho/2018 